\title{
Treatment of primary headache in children: a multicenter hospital-based study in France
}

\author{
Jean-Christophe Cuvellier · Anne Donnet · Évelyne Guégan-Massardier • \\ Fatima Nachit-Ouinekh · Dominique Parain · Louis Vallée
}

Received: 22 June 2009/ Accepted: 3 September 2009/Published online: 22 September 2009

(C) The Author(s) 2009. This article is published with open access at Springerlink.com

\begin{abstract}
The aim of this 6-month, prospective, multicenter study of 398 children and adolescents with primary headaches was to collect data on headache treatment in neuropediatric departments. Treatments were compared before and after consultation. Prior to consultation, the acute treatments that had been prescribed most frequently were paracetamol ( $82.2 \%$ of children) and non-steroidal anti-inflammatory drugs treatment $(53.5 \%) ; 10.3 \%$ had received a prophylactic treatment. No differences in either acute or prophylactic treatment with respect to headache diagnosis were observed. After the neuropediatric
\end{abstract}

On behalf of the Céleste Group.

The members of the Céleste Group are given in the Appendix.

J.-C. Cuvellier · L. Vallée

Division of Paediatric Neurology, Department of Paediatrics,

Lille Faculty of Medicine and Children's Hospital, Lille, France

A. Donnet

Department of Neurosurgery, Timone Hospital,

Marseille, France

É. Guégan-Massardier

Department of Neurology, Rouen University Hospital,

Rouen, France

F. Nachit-Ouinekh

Laboratoire GlaxoSmithKline, Marly-le-Roi, France

D. Parain

Department of Neurophysiology, Rouen University Hospital, Rouen, France

\section{J.-C. Cuvellier $(\square)$}

Service de Neuropédiatrie, Clinique de Pédiatrie, Hôpital Roger

Salengro, rue Emile Laine, Centre Hospitalier Régional et

Universitaire, 59037 Lille Cedex, France

e-mail: jc-cuvellier@chru-lille.fr consultation, paracetamol was replaced by a non-steroidal anti-inflammatory drug in about three-quarters of cases and by triptan in about one-quarter of cases. The number of children prescribed a prophylactic treatment nearly doubled, whereas there was a 5-fold and 23-fold increase in psychotherapy and relaxation training, respectively, between pre-referral and referral. We conclude that specific treatments were underused for primary headache.

Keywords Headache - Migraine - Therapy · Children

\section{Introduction}

Headache is a common problem among children and adolescents. It restricts teenage quality of life [1] and is a major cause of absence from school as well as an important factor in health-related costs among adolescents [2]. The number of population-based studies assessing the prevalence of pediatric headache is limited [3,4]. Published prevalence for primary headache disorders vary considerably, within a prevalence range of $1.0-17.0 \%$ for migraine and $0.9-72.3 \%$ for episodic tension-type headache [4].

Pediatric headache remains under-recognized, underdiagnosed and under-treated. However, the acute and prophylactic therapies commonly used for primary headache in children and adolescents are the same as those used in adults and show similar efficacy. Over the last 15 years, behavioral therapies, notably biofeedback, have become established as useful alternatives to drugs. The efficacy of these treatments has been established both by controlled studies and by long-term follow-up studies [5]. Accurate early diagnoses, as well as comprehensive and effective treatment, are essential to minimize the impact of headaches on a child's quality of life. Such interventions may 
prevent progression and lifelong consequences, including the development of comorbidities.

The Céleste study is the first cross-sectional, epidemiological, multicenter survey of primary headache in children and adolescents conducted in France. The primary objective of this study, reported in a previous paper [6], was to provide data on features of primary headache in French children and adolescents. Briefly, the typical consulting child had headache characteristics highly reminiscent of migraine. With regard to classification of headache diagnoses, according to the second edition of the International Classification of Headache Disorders (ICHD-II) [7], proposed by the International Headache Society, migraine (categories 1.1-1.6 in the ICHD-II classification) accounted for $79 \%$ of the diagnoses. For most of the diagnostic categories, the consistency of the investigator's diagnosis with the ICHD-II criteria was good or excellent. A second aim of the Céleste study was to collect data on headache treatment in neuropediatric departments. Treatments were compared before and after consultation.

\section{Methods}

This was a cross-sectional epidemiological survey of primary headache in children conducted in 22 hospital neuropediatric departments in France between November 2005 and May 2006.

\section{Participating physicians}

Investigators were recruited from the French Society for Paediatric Neurology. Physicians were selected at random from the membership list of this society and invited to participate in the study until the required number of 25 centers was reached.

\section{Patients}

The study included children aged between 2 and 16 years consulting a neuropediatric center for primary headache for the first time. Children already participating in a clinical trial or other studies were excluded. Each investigator was expected to include serially the first 25 patients, fulfilling the entry criteria and consulting at the center during a sixmonth inclusion period.

Data collection

At the consultation, a detailed clinical examination was performed. The investigators completed a questionnaire for each patient providing information on the demographic profile of the child, the headache diagnosis assigned, the clinical features of the headache, triggering factors, personal and familial medical history, and treatment. Treatments were identified from a checklist by their commercial name and categorized by pharmacological class into acute headache treatments, prophylactic treatments and nonpharmacological treatments. The investigator completed a headache feature checklist, which allowed the headache type to be classified a posteriori according to the ICHD-II classification proposed by the International Headache Society [7]. Once this had been performed, treatment was re-evaluated and a new prescription delivered where appropriate.

\section{Statistical analysis}

The size of the target study sample was determined by a priori power calculations to determine the frequency of key variables with a precision of $5 \%$ when observed in $50 \%$ of the samples. These calculations yielded a target sample size of 384 subjects. To take into account potentially non-evaluable subjects, it was decided to include 500 children. It was estimated that 20 physicians would need to include 25 children each, to include this number of patients over a 6-month period. To take into account physicians who would agree to participate but then not recruit patients, 25 investigators were considered necessary to achieve the target sample size.

The presentation of the headache treatments is purely descriptive. Inter-group comparisons between headache types were performed with the $\chi^{2}$ test or Fisher's exact test as appropriate. All tests were two sided and a probability level of $P<0.05$ was considered significant. All data were controlled, validated and analyzed centrally using SAS software, version 8.2 (SAS Institute, Cary, CA, USA).

\section{Ethics}

The study was performed according to international and French regulatory guidelines and current codes of good epidemiological practice. Since patient care was not altered by inclusion in the study, ethics committee approval was not necessary. With respect to confidentiality of patient records, data handling for the study was authorized by the Commission Nationale d'Informatique et des Libertés'.

\section{Results}

Study population

Overall, 479 children were included in the study: 252 girls (52.6\%) and 227 boys (47.4\%). The mean age of the study population was $9.8 \pm 3.1$ years (median, 10 years; range, 
2-10 years). Of these children, 88 presented with multiple types of headache. The remaining 398 children who presented with a single type of headache represent the study population for the analysis of treatments. In this group, the three most frequent headache diagnoses were migraine without aura (195 children; $50.4 \%$ ), probable migraine (50 children; $12.9 \%$ ) and migraine with aura (44 children; $11.4 \%)$. For the purposes of this analysis of treatments, the remaining 98 children with other diagnoses were combined into an 'other headache' group. For 11 children, no specific diagnosis was provided.

Acute headache treatments

At the time of the consultation, acute headache treatments were being prescribed to 376 children $(94.5 \%$ of the sample). The type of treatment prescribed is presented by age group in Table 1 and by headache diagnosis as assigned by the physician in Table 2 . The acute treatments most frequently prescribed were paracetamol (82.2\% of children) and non-steroidal anti-inflammatory drugs (53.5\%). Specific headache treatments were prescribed infrequently, namely ergot alkaloids to 6 children $(1.5 \%)$ and triptans to 12 children (3.0\%). No distinct patterns of prescribing were observed with respect to age, although the youngest children (younger than 9 years) were more frequently untreated (10.7\% of this age group). With respect to headache diagnosis, ergot alkaloids and triptans were prescribed more frequently to patients assigned a diagnosis of migraine with or without aura by the physician.

\section{Prophylactic treatments}

A total of 41 children were receiving a prophylactic treatment at the time of consultation (10.3\%), principally an ergot alkaloid or an antiserotonergic drug (Table 1). Prophylactic treatments were given most frequently to children assigned a diagnosis of migraine without aura (Table 2). However, regardless of treatment, only a minority of children were reported to gain benefit in terms of a reduction in the frequency of headaches of at least $50 \%$ or a reduction in perceived pain intensity (Table 3). The treatment was generally considered to be well tolerated.

Non-pharmacological treatment

At the time of consultation, nine children had participated in psychotherapy and three in relaxation techniques, to manage their headaches, for a mean duration of $17.6 \pm$ 25.7 months (median, 18 months) and $2.0 \pm 1.4$ months (median, 2 months), respectively. However, a reduction in headache frequency of at least $50 \%$ was only reported for one child using psychotherapy, and a reduction in headache
Table 1 Headache treatments according to age

\begin{tabular}{|c|c|c|c|c|}
\hline & $\begin{array}{l}<9 \text { years } \\
N=150\end{array}$ & $\begin{array}{l}9-12 \text { years } \\
N=161\end{array}$ & $\begin{array}{l}>12 \text { years } \\
N=87\end{array}$ & $\begin{array}{l}\text { Total } \\
N=398\end{array}$ \\
\hline \multicolumn{5}{|c|}{ Acute headache treatments, $n(\%)$} \\
\hline NSAIDS & $66(44.0)$ & 99 (61.5) & $48(55.2)$ & $213(53.5)$ \\
\hline Paracetamol & $115(76.7)$ & $135(83.9)$ & $77(88.5)$ & $327(82.2)$ \\
\hline Ergot alkaloid & $1(0.70)$ & $4(2.5)$ & $1(1.2)$ & $6(1.5)$ \\
\hline Triptan & None & $4(2.5)$ & $8(9.2)$ & $12(3.0)$ \\
\hline Analgesics & $1(0.7)$ & $3(1.9)$ & $1(1.2)$ & $5(1.3)$ \\
\hline None & $16(10.7)$ & $4(2.5)$ & $2(2.3)$ & $22(5.5)$ \\
\hline \multicolumn{5}{|c|}{ Prophylactic treatments, $n(\%)$} \\
\hline Antiserotonergics & $2(1.3)$ & $8(5.0)$ & $6(6.9)$ & $16(4.0)$ \\
\hline Tricyclics & None & $1(0.6)$ & None & $1(0.3)$ \\
\hline Beta blockers & None & $1(0.6)$ & $1(1.2)$ & $2(0.5)$ \\
\hline Ca channel blockers & $1(0.7)$ & $2(1.2)$ & $1(1.2)$ & $4(1.0)$ \\
\hline Ergot alkaloids & $4(2.7)$ & $12(7.5)$ & $12(13.8)$ & $28(7.0)$ \\
\hline Antiepileptic drugs & $1(0.7)$ & $1(0.6)$ & None & $2(0.5)$ \\
\hline No prophylaxis & $145(96.7)$ & $140(87.0)$ & $72(82.8)$ & $357(89.7)$ \\
\hline
\end{tabular}

Categories are non-exclusive, since children could be prescribed more than one treatment

intensity by two children using psychotherapy and one using relaxation techniques.

Re-evaluation of diagnosis and treatment

Following completion of the headache feature checklist, the diagnosis was re-assigned a posteriori using the ICHDII classification. Fully exploitable data were obtained for 313 children ( $78.6 \%$ of the sample). In general, a high concordance was observed between the physician's diagnosis and the ICHD-II classification. These data have been presented in extenso elsewhere [6]. For the three headache diagnoses considered here, the concordance ranged from $85.4 \%$ for migraine without aura to $95.4 \%$ for migraine with aura. The distribution of treatments prescribed at the time of consultation among the three ICHD-II diagnostic groups was similar to their distribution among the original physician-assigned diagnoses (data not shown).

At the end of the consultation, headache medication prescription was revised. With respect to acute headache treatments, analgesic medication was stopped in all cases and paracetamol stopped in three-quarters of the children originally prescribed this treatment (Table 4). In $75.7 \%$ of these children, a non-steroidal anti-inflammatory drug was substituted, together with triptan in $24.3 \%$ of cases, or medication was stopped altogether (22.2\%). The number of children prescribed triptan increased nearly sixfold, principally due to initiation of treatment in children previously prescribed a non-steroidal anti-inflammatory drug or paracetamol. In parallel, the number of children prescribed a prophylactic treatment nearly doubled from 34 to 64 . This 
Table 2 Headache treatments according to physician diagnosis

\begin{tabular}{|c|c|c|c|c|c|}
\hline & $\begin{array}{l}\text { Probable migraine } \\
N=50\end{array}$ & $\begin{array}{l}\text { Migraine with aura } \\
N=44\end{array}$ & $\begin{array}{l}\text { Migraine without aura } \\
N=195\end{array}$ & $\begin{array}{l}\text { Other headaches } \\
N=98\end{array}$ & $\begin{array}{l}\text { Total } \\
N=387\end{array}$ \\
\hline \multicolumn{6}{|c|}{ Acute headache treatments, $\mathrm{n}(\%)$} \\
\hline NSAIDS & $19(38.0)$ & $26(59.1)$ & $115(59.0)$ & $49(50.0)$ & $209(54.0)$ \\
\hline Paracetamol & $40(80.0)$ & $39(88.6)$ & $162(83.1)$ & $80(81.6)$ & $321(83.0)$ \\
\hline Ergot alkaloid & None & $2(4.6)$ & $3(1.5)$ & $1(1.0)$ & $6(1.6)$ \\
\hline Triptan & None & $1(2.3)$ & $10(5.1)$ & $1(1.0)$ & $12(3.1)$ \\
\hline Analgesics & $1(2.0)$ & $2(4.6)$ & $1(0.5)$ & $1(1.0)$ & $5(1.3)$ \\
\hline None & $3(6.0)$ & $1(2.3)$ & $5(2.6)$ & $10(10.2)$ & $19(4.9)$ \\
\hline \multicolumn{6}{|c|}{ Prophylactic treatments, $n(\%)$} \\
\hline Antiserotonergics & $1(2.0)$ & None & $12(6.2)$ & $2(2.0)$ & $15(3.9)$ \\
\hline Tricyclics & None & None & None & $1(1.0)$ & $1(0.3)$ \\
\hline Beta blockers & None & None & $2(1.0)$ & None & $2(0.5)$ \\
\hline $\mathrm{Ca}$ channel blockers & None & None & $2(1.0)$ & $2(2.0)$ & $4(1.0)$ \\
\hline Ergot alkaloids & $4(8.0)$ & $2(4.6)$ & $16(8.2)$ & $5(5.1)$ & $27(7.0)$ \\
\hline Antiepileptic drugs & $1(2.0)$ & None & None & $1(1.0)$ & $2(0.5)$ \\
\hline No prophylaxis & $45(90.0)$ & $42(95.5)$ & $170(87.2)$ & $91(92.9)$ & $348(89.9)$ \\
\hline
\end{tabular}

Categories are non-exclusive, since children could be prescribed more than one treatment. Data on diagnosis were missing for 11 children

Table 3 Perceived efficacy and tolerance of headache prophylaxis

\begin{tabular}{lrlll}
\hline Treatment class & $N$ & Reduced frequency, $n(\%)$ & Reduced pain, $n(\%)$ & Well tolerated, $n(\%)$ \\
\hline Antiserotonergics & 16 & $5(31.3)$ & $3(18.8)$ & $7(43.8)$ \\
Tricyclic & 1 & None & None & $1(100.0)$ \\
Beta blocker & 2 & $1(50.0)$ & None & $1(50.0)$ \\
Ca channel blocker & 4 & None & None & $1(25.0)$ \\
Ergot alkaloid & 28 & $7(25.0)$ & $7(25.0)$ & $18(64.3)$ \\
Antiepileptic drug & 2 & None & $1(50.0)$ & None \\
\hline
\end{tabular}

increase was with regard to all classes of prophylactic medication, with the exception of ergot alkaloids, which were stopped in half the children prescribed these drugs (Table 4). The most frequently prescribed class of prophylactic treatment was antiserotonergic drugs, accounting for $43.8 \%$ of all prescriptions. Likewise, prescription of non-pharmacological treatments also increased markedly, with psychotherapy being offered to 33 children compared to 7 previously, relaxation techniques being proposed to 43 compared to 2 , and biofeedback started in 8 children.

\section{Discussion}

This was the second part of the Céleste study, the first cross-sectional, epidemiological, multicenter survey of primary headache in children and adolescents, conducted in France. The results presented in this article concentrated specifically on the therapeutic management of primary headache in children and adolescents, with a comparison between pre-referral and referral conditions.
Both migraine and tension-type headache require a comprehensive treatment plan, which may include acute and preventive therapy. The American Academy of Neurology recently reviewed the available evidence for both acute and preventive migraine therapies in detail, either behavioral or pharmaceutical, in a Practice Parameter [8]. In children of age 6-12 years, both paracetamol at $15 \mathrm{mg} / \mathrm{kg}$ per dose or the non-steroidal anti-inflammatory drug ibuprofen at $7.5-10 \mathrm{mg} / \mathrm{kg}$ per dose, taken when needed, are effective and well tolerated [9, 10]. For the acute treatment of migraine in adolescents of age 12-17 years, in addition to ibuprofen, sumatriptan nasal spray at doses of 5-20 mg is effective and well tolerated [11]. Triptans, migraine-specific medications, may be added to the treatment plan when children have a moderate-to-severe migraine, when the response to ibuprofen is either incomplete or ineffective. Management of tension-type headaches involves the use of intermittent analgesics coupled with behavior interventions such as stress management. Both paracetamol and non-steroidal anti-inflammatory drugs are effective first-line therapy for episodic tension-type 
Table 4 Original and revised headache treatments

\begin{tabular}{|c|c|c|c|}
\hline & $\begin{array}{l}\text { Original } \\
\text { treatment, } n(\%)\end{array}$ & $\begin{array}{l}\text { Revised } \\
\text { treatment, } n(\%)\end{array}$ & Change \\
\hline \multicolumn{4}{|c|}{ Acute headache treatments } \\
\hline NSAIDS & $175(55.9)$ & $202(64.5)$ & 1.15 \\
\hline Paracetamol & $260(83.1)$ & $66(21.1)$ & 0.25 \\
\hline Ergot alkaloid & $5(1.6)$ & $3(1.0)$ & 0.60 \\
\hline Triptan & $9(2.9)$ & $58(18.5)$ & 6.44 \\
\hline Analgesics & $4(1.3)$ & None & - \\
\hline None & $16(5.1)$ & $43(13.7)$ & 2.69 \\
\hline \multicolumn{4}{|l|}{ Prophylactic treatments } \\
\hline Antiserotonergics & $13(4.2)$ & $28(9.0)$ & 2.15 \\
\hline Tricyclics & $1(0.3)$ & $8(2.6)$ & 8.00 \\
\hline Beta blockers & $1(0.3)$ & $5(1.6)$ & 5.00 \\
\hline Ca channel blockers & $4(1.3)$ & $7(2.2)$ & 1.75 \\
\hline Ergot alkaloids & $25(8.0)$ & $14(4.5)$ & 0.56 \\
\hline Antiepileptic drugs & $2(0.6)$ & $2(0.6)$ & 1.00 \\
\hline No prophylaxis & $279(89.1)$ & 249 (79.6) & 0.89 \\
\hline \multicolumn{4}{|c|}{ Non-pharmacological treatments } \\
\hline Psychotherapy & $7(2.2)$ & $33(10.5)$ & 4.71 \\
\hline Relaxation & $2(0.6)$ & $43(13.7)$ & 21.50 \\
\hline Biofeedback & None & $8(2.6)$ & - \\
\hline
\end{tabular}

Data are presented for the 313 children for whom an ICHD-II headache diagnosis could be assigned. Categories are non-exclusive, since children could be prescribed more than one treatment. The 'change' column represents the ratio between the revised treatment and the original treatment

headache [12]. The clinical characteristics and treatment options in cluster headache are globally similar to those of adult patients [13].

In France, the French Health Agency (Haute Autorité de Santé, HAS) published clinical guidelines for the therapeutic management of migraines in adults and children. These were distributed to each general practitioner (GP) in October 2002 [14]. The HAS recommended ibuprofen $(7.5-10 \mathrm{mg} / \mathrm{kg})$ as the mainstay drug for acute migraine attacks in children aged 6 months or older [14]. If ibuprofen proved ineffective, the HAS recommended the use of ergot derivatives from the age of 10 years onward, despite the absence of evidence of efficacy $[15,16]$, and the use of sumatriptan nasal spray from the age of 12 years onwards. In France, sumatriptan nasal spray is the only triptan approved for migraine treatment of children and adolescents 12 years or older. In this context, it is astonishing that paracetamol was largely preferred by GPs. Moreover, paracetamol was unsatisfactory in the majority of cases. Perhaps the most striking finding of our study was the fact that there was globally no distinct pattern of prescribing with respect to diagnosis. Paracetamol was the leading acute treatment that was indistinctly used for migraine, tension-type headache or other primary headaches. Specific antimigraine drugs were equally underused, although ergot alkaloids and triptans were prescribed slightly more frequently to patients assigned a diagnosis of migraine with or without aura by their physician. Not surprisingly, the acute treatment prescribed following the consultation in the neuropediatric department was more suited to the diagnosis and more in line with present recommendations, either by the HAS or the American Academy of Neurology, with a nearly sixfold increase in triptan prescription.

The decision to initiate prophylactic therapy must take into account the disability caused by the headache disorder. There is currently, however, no consensus on when to initiate preventive measures; but daily prophylactic therapy is warranted in about $20-30 \%$ of young migraineurs [17]. Most authors consider three to four migraines per month as the threshold for initiating prophylactic treatment in pediatric patients. Prophylactic pharmacological treatment should be also considered in chronic tension-type headache if non-pharmacological management is inadequate.

Prophylactic pharmacological headache treatments can be classified into antiepileptic medications, antidepressant medications, antiserotonergic medications and antihypertensive medications, including both beta blockers and calcium-channel blockers. Around $10 \%$ of children were prescribed a prophylactic therapy. There was slight difference with respect to diagnosis, the only exception being migraine with aura. GPs largely favored "old" prophylactic medications, with ergot alkaloids and serotonin antagonists being the two classes of drug they most often prescribed. Dihydroergotamine remains one of the drugs prescribed most often for childhood migraine prophylaxis in western European countries, such as France or Germany, despite lack of any proof of its efficacy. To our knowledge, only one controlled study with dihydroergotamine drops has been reported in a pediatric population, which found no statistical difference between placebo and dihydroergotamine [18]. Oxetorone, pizotifen and cyproheptadine were the serotonin antagonists prescribed by GPs. The Practice Parameter stated in its conclusions that pizotifen did not show efficacy and was not recommended and that there was insufficient evidence to make any recommendations concerning the use of cyproheptadine [8]. No study regarding the use of oxetorone in children is available. Nevertheless, the three drugs have been recommended by the HAS, which stated at the same time that there was actually no evidence of their efficacy [14]. In this setting it is not astonishing that the perceived efficacy by the patients was poor. Both serotonin antagonists and ergot alkaloids reduced frequency of headache frequency in less than a third of cases. Newer prophylactic drugs, such as antiepileptic medications, were rarely prescribed by GPs. While 
the number of children prescribed a prophylactic treatment nearly doubled following the consultation in the neuropediatric department, it is surprising that neuropediatricians also favored "old-fashioned" prophylactic medications. Antiserotonergic drugs were used most often, whereas newer ones such as antiepileptic medications, for which the evidence base for efficacy is considerably more solid, were infrequently prescribed.

Behavioral headache treatments include relaxation training, biofeedback training, cognitive-behavioral therapy or combinations of these treatments [19]. The availability of these therapies is limited in France and this may explain why few patients benefited from nonpharmacologic treatments at referral. Nevertheless, following the re-evaluation by a neuropediatrician, non-pharmacologic rather than drug treatments accounted for much of the increase in headache prevention therapy. Whereas there was a nearly 2 -fold increase in the prescription of prophylactic medication, there was a 5-fold and a 23-fold increase for both psychotherapy and relaxation training, respectively, whereas biofeedback prescription increased from 0 to 8 patients, between pre-referral and referral. This may also indicate that there is a lack of knowledge of the possibility of these therapeutic options by GPs.

The reasons for our findings are difficult to understand, in view of scientific progress in the field of headache and the efforts made by professional societies to improve the standard of treatment [20]. GPs seem reluctant to be involved strongly or directly in the management of primary headache, especially in children, and prefer to delegate specialists to prescribe treatments that require a precise diagnosis [21].

\section{Conclusion}

The present study is the first cross-sectional, epidemiological, multicenter survey of primary headache, in children and adolescents, conducted in France. It has provided some insight into the management of primary headache in French children and adolescents by general practitioners. Paracetamol is still widely prescribed despite the availability of specific antimigraine drugs, such as triptans. Based on the prevalence and epidemiology of pediatric primary headaches, it is clear that general practitioners play a key role in the successful management of those patients who do not require specialized neurological treatment. More treatment should be individualized using a stratified care regimen, and general practitioners should be more vigilant to prevent migraine progression to chronic daily headache. Such improvement requires continuing education for general practitioners.
Acknowledgments We thank Laboratoire GlaxoSmithKline, France, for its contribution to the implementation and data analysis for this study.

\section{Conflict of interest None.}

Open Access This article is distributed under the terms of the Creative Commons Attribution Noncommercial License which permits any noncommercial use, distribution, and reproduction in any medium, provided the original author(s) and source are credited.

\section{Appendix}

\section{Céleste Study Group}

Patrick Berquin, MD; Jacques Boulloche, MD; Jean-Paul Carrière, MD; Denys Chaigne, MD; Geneviève Demarquay, MD; Caroline Espil-Taris, MD; Sonia Finck, MD; Pierre Landrieu, MD; Marie-Odile Livet, MD; Catherine Louvet Giendaj, MD; Josette Mancini, MD; Pierre M'Bula, MD; Florence Meaulle, MD; Patricia Munoz-Lacoste, MD; Marie-José Penniello-Valette, MD; Sylviane Peudenier, MD; François Pouplard, MD; Christophe Rousselle, MD; Loïc Rambaud, MD; Pascal Sabouraud, MD.

\section{References}

1. Latham J, Davies BD (1994) The socioeconomic impact of chronic pain. Disabil Rehabil 16:39-44

2. Frölund F, Frölund C (1986) Pain in general practice: pain as a cause of patient-doctor contact. Scand J Prim Health Care 4:97100

3. Anttila P, Metsähonkala L, Sillanpää M (2006) Long-term trends in the incidence of headache in Finnish schoolchildren. Pediatrics 117:e1197-e1201

4. Zwart JA, Dyb G, Holmen TL, Stovner LJ, Sand T (2004) The prevalence of migraine and tension-type headaches among adolescents in Norway, the Nord-Trøndelag Health Study (HeadHUNT-Youth): a large population-based epidemiological study. Cephalalgia 24:373-379

5. Andrasik F, Larsson B, Grazzi L (2002) Biofeedback treatment of recurrent headaches in children and adolescents. In: Guidetti V, Russell G, Sillanpää M, Winner P (eds) Headache and migraine in childhood and adolescence. Martin Dunitz, London, pp 317322

6. Cuvellier JC, Donnet A, Guégan-Massardier E, Nachit-Ouinekh F, Parain D, Vallée L (2008) Clinical features of primary headache in children: a multicentre hospital-based study in France. Cephalalgia 28:1145-1153

7. Headache Classification Committee (2004) The international classification of headache disorders, cranial neuralgia and facial pain, 2nd edition. Cephalalgia 24(Suppl 1):1-160

8. Lewis D, Ashwal S, Hershey A, Hirtz D, Yonker M, Silberstein S, American Academy of Neurology Quality Standards Subcommittee, Practice Committee of the Child Neurology Society (2004) Practice parameter: pharmacological treatment of migraine headache in children and adolescents, report of the 
American Academy of Neurology Quality Standards Subcommittee and the Practice Committee of the Child Neurology Society. Neurology 63:2215-2224

9. Hämäläinen ML, Hoppu K, Valkeila E, Santavuori P (1997) Ibuprofen or acetaminophen for the acute treatment of migraine in children: a double-blind, randomized, placebo-controlled, crossover study. Neurology 48:103-107

10. Lewis DW (2002) Children's ibuprofen suspension for the acute treatment of pediatric migraine. Headache 42:780-786

11. Silver S, Gano D, Gerretsen P (2008) Acute treatment of paediatric migraine: a meta-analysis of efficacy. J Paed Child Health 44:3-9

12. Anttila P (2006) Tension-type headache in childhood and adolescence. Lancet Neurol 5:268-274

13. Lewis DW (2002) Headaches in children and adolescents. Am Fam Physician 65:625-632

14. Agence Nationale d'Accréditation et d'Evaluation en Santé (ANAES) (2003) Recommandations pour la pratique clinique. Prise en charge diagnostique et thérapeutique de la migraine chez l'adulte et l'enfant Rev Neurol 159:126-135

15. Congdon PJ (1979) Migraine in childhood: a study of 300 children. Dev Med Child Neurol 21:209-216
16. Hämäläinen ML, Hoppu K, Santavuori PR (1997) Oral dihydroergotamine for therapy-resistant migraine attacks in children. Pediatr Neurol 16:114-117

17. Lewis DW, Diamond S, Scott D, Jones V (2004) Prophylactic treatment of pediatric migraine. Headache 44:230-237

18. Pothmann R (2002) Medical prophylaxis in childhood migraine. In: Guidetti V, Russell G, Sillanpää M, Winner P (eds) Headache and migraine in childhood and adolescence. Martin Dunitz, London, pp 251-256

19. Eccleston C, Morley S, Williams A, Yorke L, Mastroyannopoulou K (2002) Systematic review of randomized controlled trials of psychological therapy for chronic pain in children and adolescents, with a subset meta-analysis of pain relief. Pain 99:157-165

20. Lewis DW, Scott D, Rendin V (2002) Treatment of paediatric headache. Expert Opin Pharmacother 3:1433-1442

21. Ferrari A, Pasciullo G, Savino G, Cicero AF, Ottani A, Bertolini A, Sternieri E (2004) Headache treatment before and after the consultation of a specialized centre: a pharmacoepidemiology study. Cephalalgia 24:356-362 